\title{
Mechanosynthesis of amides in the total absence of organic solvent from reaction to product recovery $\dagger \neq$
}

\author{
Thomas-Xavier Métro,* Julien Bonnamour, Thomas Reidon, Jordi Sarpoulet, Jean Martinez \\ and Frédéric Lamaty*
}

The synthesis of various amides has been realised avoiding the use of any organic solvent from activation of carboxylic acids with CDI to isolation of the amides. Mechanochemistry was the key point of the process allowing rapid formation of the amide bond and efficient water-based purification of the final products.

Solvent-free synthesis is probably the most efficient way to improve the "greenness" of complex organic molecule syntheses as the solvent is generally the main source of waste. ${ }^{1}$ Excluding solvent from the reaction medium has led to an ever-growing use of the ball-mill as a practical tool for efficient mixing of solid-containing reaction mixtures. ${ }^{2}$ Mechanochemistry-based approaches also proved to be more selective and efficient than the solvent-based versions in a wide range of reactions. ${ }^{3}$ Nevertheless, as noticed by James et al. in a recent review, ${ }^{3}$ it is "clearly unrealistic that mechanochemistry could make all of chemical synthesis completely solvent-free". Indeed, an overwhelming majority of the mechanochemistry-based methodologies requires solvent for recovery and purification of the products, thereby attenuating the interest of these solvent-free syntheses. A very limited number of mechanochemistry-based methodologies describe complete solvent-free processes. ${ }^{4}$ Unfortunately, they are limited to inherently simple reactions such as addition or condensation reactions producing water as the only by-product, rendering the purification step unnecessary. Recently, a solvent-free process including solventfree synthesis, product recovery and purification was described by Halasz and coworkers. ${ }^{5}$ While being a real breakthrough in the development of complete solvent-free syntheses of high added-value molecules, the solvent-free purification of this process was based on sublimation of the products, thereby limiting the possible extension of this approach to the narrow range of molecules possessing high vapor pressure properties.

We would like to detail here the results of our recent studies in the development of complete solvent-free processes for high

Institut des Biomolécules Max Mousseron, UMR 5247 Université Montpellier 1 et Université Montpellier 2-CNRS, Place Eugène Bataillon, 34095 Montpellier Cedex 05, France.

E-mail: txmetro@um2.fr,frederic.lamaty@univ-montp2.fr added-value molecules production. Pursuing our interest in the development of solvent-free amide bond formation, ${ }^{6}$ we found that solvent-free synthesis of amides resulting from activation of carboxylic acids with $N, N^{\prime}$-carbonyldiimidazole (CDI) can be combined with solvent-free purification and recovery. We built our strategy on the great water solubility difference between the hydrophobic amides and the hydrophilic side-products of the reaction, which are amines, carboxylic acids and imidazole. Among the commonly used coupling reagents, $N, N^{\prime}$-carbonyldiimidazole (CDI) appeared as the most promising reagent. It is cheap, readily available in large quantities and produces relatively benign and easily separable by-products (carbon dioxide and imidazole). To our knowledge, only one study has been previously published concerning the solvent-free formation of amide bonds from carboxylic acids and amines using CDI. ${ }^{7}$ In this case, mixing was realised with a spatula, which may raise serious problems in a scale-up perspective. Additionally, products were recovered using EtOAc, which is of limited interest as the formation of the studied products can be easily realised in EtOAc. ${ }^{8}$

We started our study by treating hydrocinnamic acid with 1.0 eq. CDI for $5 \mathrm{~min}$ in a ball-mill, followed by the addition of 0.9 eq. benzylamine hydrochloride and mixing for $10 \mathrm{~min}$ (Scheme 1). Consumption of both the carboxylic acid in the first step and the acyl-imidazole in the second step was followed in the solid-state by disappearance of their IR bands (1692 and $1730 \mathrm{~cm}^{-1}$ respectively). Deionised water was added into the milling jar and 5 min ball-mill mixing furnished a fine suspension, which rendered isolation of pure $N$-benzylhydrocinnamide by filtration very easy. As by-products (imidazole, unreacted carboxylic acid and amine) were more soluble in water than

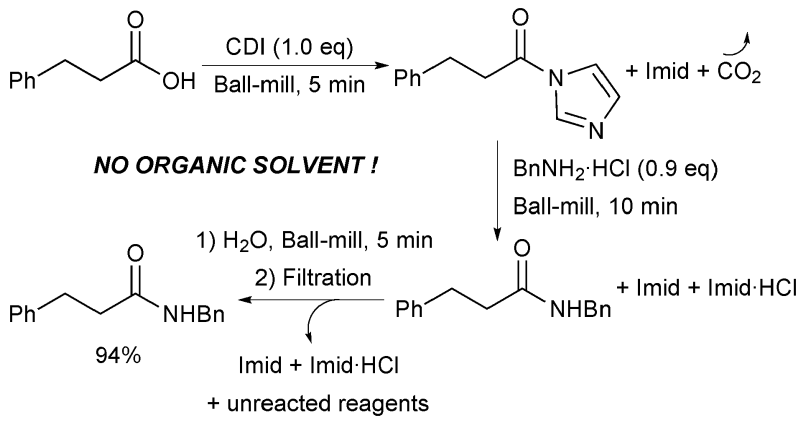

Scheme 1 Solvent-free synthesis of $N$-benzylhydrocinnamide. 
Table 1 Exemplification of the solvent-free CDI-mediated mechanosynthesis of amides ${ }^{a}$

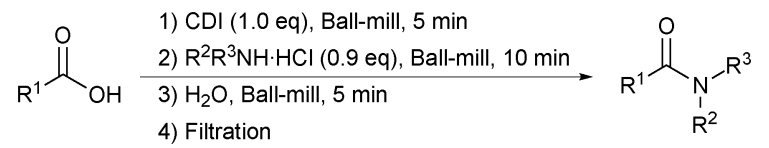<smiles>CCCCCC(=O)NCc1ccccc1</smiles><smiles>O=C(Cc1ccccc1)NCc1ccccc1</smiles><smiles>O=C(CCCc1ccccc1)NCc1ccccc1</smiles><smiles>O=C(NCc1ccccc1)C1C2CC3CC(C2)CC1C3</smiles><smiles>Cc1c(CC(=O)NCc2ccccc2)cccc1[N+](=O)[O-]</smiles><smiles>O=C(NCc1ccccc1)c1ccccc1</smiles><smiles>O=C(NCCc1ccccc1)c1ccccc1</smiles><smiles>O=C(NOCc1ccccc1)c1ccccc1</smiles><smiles>O=C(NNc1ccccc1)c1ccccc1</smiles><smiles>O=C(CCc1ccccc1)Nc1ccccc1</smiles><smiles>CC(NC(=O)c1ccccc1)c1ccccc1</smiles>

$68 \%(99 \% \mathrm{ee})^{\mathrm{c}}$<smiles>CCOC(=O)C(Cc1ccccc1)NC(=O)c1ccccc1</smiles>

$78 \% \mathrm{~d}(98 \% \mathrm{ee})^{\mathrm{c}}$<smiles>CC(NC(=O)[C@@H](Cc1ccccc1)NC(=O)OC(C)(C)C)c1ccccc1</smiles>

$49 \%{ }^{\mathrm{d}, \mathrm{e}}(>95 \% \mathrm{de})^{\mathrm{f}}$<smiles>COc1ccc2cc([C@@H](C)C(=O)N[C@H](C)c3ccccc3)ccc2c1</smiles>

$81 \%{ }^{e}(>95 \% d e)^{f}$

${ }^{a}$ Realised on the 1.35 mmole scale. ${ }^{b}$ Completed within 6 h. ${ }^{c}$ Determined by chiral HPLC. See ESI for details. ${ }^{d}$ Completed within 30 min. ${ }^{e}$ Starting from free amine. ${ }^{f}$ Determined by ${ }^{1} \mathrm{H}$ and ${ }^{13} \mathrm{C}$ NMR. No signal corresponding to the diastereoisomer was observed.

the resulting amide, the latter could be recovered in a pure form in $94 \%$ yield. Under these optimised conditions, various amides could be synthesised and isolated without the use of any organic solvent (Table 1).

Non-substituted carboxylic acids could be transformed into their corresponding $N$-benzyl amides with excellent yields (Table 1 , compounds 1-3). High steric hindrance was not an obstacle as bulky 1-adamantane carboxylic acid could be easily activated with CDI to furnish the corresponding $N$-benzyl amide in good yield (Table 1, compound 4). Heteroatom-containing $N$-benzyl amides such as compounds $\mathbf{5}$ and $\mathbf{6}$ could be isolated with high yield. Differently substituted amines could also be benzoylated with high yields (Table 1, compounds 7-9). This methodology was not limited to the acylation of primary amine hydrochlorides because $O$-benzyl hydroxylamine, phenylhydrazine and dibenzylamine hydrochlorides were easily acylated (Table 1, compounds 10-12). In the latter case the process is less efficient, compound $\mathbf{1 2}$ was obtained in $44 \%$ yield after $6 \mathrm{~h}$ reaction. Finally, it is worth noting that no racemisation was observed when using either enantiopure amines or enantiopure carboxylic acids indicating that this process was highly stereoselective (Table 1, compounds 13-16).

Anilines are known to be slow-reacting substrates considering the addition on acyl-imidazole intermediates. ${ }^{8}$ As the speed of reaction increases with concentration, removing the solvent from the reaction media could have an accelerating effect, as long as the presence of solids in the reaction media may not lead to mass transfer limitations. In order to address this point, we carefully examined aniline substrates and compared the results obtained with and without solvent (Table 2).

While $3 \mathrm{~h}$ in boiling EtOAc was necessary to transform $86 \%$ of 2-phenylpropanoic acyl-imidazole into $N$-phenyl-2phenylpropanoic amide, ${ }^{8}$ the solvent-free procedure could deliver the product 18 times faster, within 10 min only (Table 2 , entry 1 ). The difference is even more pronounced when using a less reactive substrate such as 4-(trifluoromethyl)aniline hydrochloride. In this case, benzoylation of the latter aniline was completed after $29 \mathrm{~h}$ at $50{ }^{\circ} \mathrm{C}$ in NMP. Repeating the same reaction without this toxic solvent furnished the same compound 58 times faster, in 30 min only (Table 2, entry 3 ). These results clearly showed that under solvent-free conditions combined with ball-mill induced mixing, possible mass transfer limitations related to solid-containing viscous or sticky reaction media were not significant compared to the sharp increase in the reaction speed caused by the substantially higher concentrated reaction mixture.

We then decided to study the scalability of this solvent-free methodology. To address this point, the synthesis of $N$-benzylbenzamide was performed on a $4.5 \mathrm{~g}$ scale (Scheme 2). When mixing $25 \mathrm{mmol}$ of benzoic acid with $25 \mathrm{mmol}$ of CDI in a $250 \mathrm{~mL}$ stainless steel jar containing 50 balls ( $10 \mathrm{~mm}$ diameter), the reaction finished within $5 \mathrm{~min}$, and subsequent consumption of $22.5 \mathrm{mmol}$ of benzylamine hydrochloride was completed within $10 \mathrm{~min}$, affording $4.5 \mathrm{~g}$ of $N$-benzylbenzamide ( $96 \%$ yield). This result clearly showed that this methodology was applicable at the multi-gram scale.

With these results in hand, we decided to apply the methodology to the synthesis of Teriflunomide (also known as A77 1726), an active pharmaceutical ingredient recently approved by the FDA for multiple sclerosis therapy. ${ }^{10}$ The amide bond of Teriflunomide was first synthesised by solvent-free treatment of 5-methyl-4-isoxazolecarboxylic acid with CDI for $20 \mathrm{~min}$, followed by reaction with 4-(trifluoromethyl)aniline hydrochloride for $5 \mathrm{~h}$ (Scheme 3). Addition of deionised water and 5 min mixing in the ball-mill yielded a fine suspension that was 
Table 2 Reaction with aniline hydrochloride derivatives<smiles>[R]C(=O)Nc1ccc([R])cc1</smiles>

Entry

${ }^{a}$ Reaction time to reach $86 \%$ conversion for entry 1 and $>90 \%$ conversion for entries $2-4 .{ }^{b}$ See ref. $8 .{ }^{c}$ See ref. 9. ${ }^{d}$ From 4 -aminobenzonitrile.

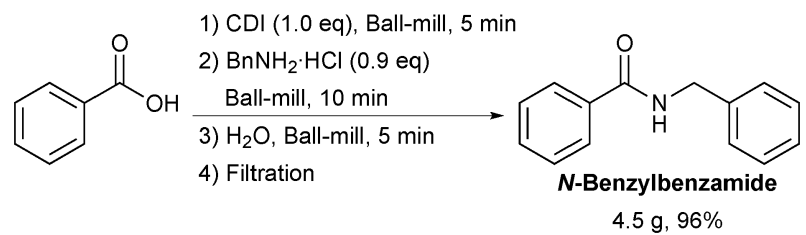

Scheme 2 Multi-gram solvent-free synthesis of $N$-Benzylbenzamide.

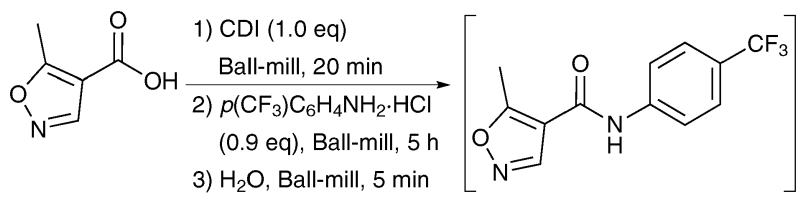

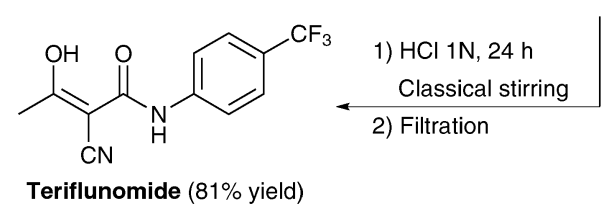

Scheme 3 Solvent-free synthesis of Teriflunomide.

easily transferred to a round-bottom flask and subjected to classical stirring. Opening of the isoxazole ring was realised by adjusting the $\mathrm{pH}$ to 1 with concentrated hydrochloric acid followed by $24 \mathrm{~h}$ stirring. Finally, simple filtration of the suspension afforded Teriflunomide with $81 \%$ yield.

Fast and efficient synthesis of amides could be realised by activation of carboxylic acids with CDI followed by reaction with amine hydrochlorides in the complete absence of any organic solvent. The methodology allowed purification and recovery of the desired products without solvent except water. Performing reactions in solvent-free media led to a sharp increase in the speed of acylation of aniline hydrochlorides compared to reactions carried out in solution. This approach was efficiently applied to the synthesis of the active pharmaceutical ingredient Teriflunomide that was obtained in $81 \%$ yield in two steps. Further studies of this complete solvent-free approach to other reactions are currently underway.

CNRS, Université Montpellier 1 (post-doctoral grant to J.B.) and Université Montpellier 2 are gratefully acknowledged for their financial support.

\section{Notes and references}

1 C. Jimenez-Gonzalez, C. S. Ponder, Q. B. Broxterman and J. B. Manley, Org. Process Res. Dev., 2011, 15, 912.

2 B. Rodríguez, A. Bruckmann, T. Rantanen and C. Bolm, Adv. Synth. Catal., 2007, 349, 2213; A. Stolle, T. Szuppa, S. E. S. Leonhardt and B. Ondruschka, Chem. Soc. Rev., 2011, 40, 2317; T. Friščić, Chem. Soc. Rev., 2012, 41, 3493.

3 S. L. James, C. J. Adams, C. Bolm, D. Braga, P. Collier, T. Friščić, F. Grepioni, K. D. M. Harris, G. Hyett, W. Jones, A. Krebs, J. Mack, L. Maini, A. G. Orpen, I. P. Parkin, W. C. Shearouse, J. W. Steedk and D. C. Waddelli, Chem. Soc. Rev., 2012, 41, 413.

4 G. Kaupp, J. Schmeyers, M. R. Naimi-Jamala, H. Zoz and H. Ren, Chem. Eng. Sci., 2002, 57, 763; G. Kaupp, M. R. Naimi-Jamal and V. Stepanenko, Chem.-Eur. J., 2003, 9, 4156; G. Kaupp, M. R. Naimi-Jamal and J. Schmeyers, Tetrahedron, 2003, 59, 3753; J. Mokhtari, M. R. Naimi-Jamal, H. Hamzeali, M. G. Dekamin and G. Kaupp, ChemSusChem, 2009, 2, 248; P. Nun, C. Martin, J. Martinez and F. Lamaty, Tetrahedron, 2011, 67, 8187.

5 I. Huskić, I. Halasz, T. Friščić and H. Vančik, Green Chem., 2012, $14,1597$.

6 V. Declerck, P. Nun, J. Martinez and F. Lamaty, Angew. Chem., Int. Ed., 2009, 48, 9318.

7 S. K. Verma, R. Ghorpade, A. Pratap and M. P. Kaushik, Tetrahedron Lett., 2012, 53, 2373.

8 P. J. Dunn, W. Hoffmann, Y. Kang, J. C. Mitchell and M. J. Snowden, Org. Process Res. Dev., 2005, 9, 956.

9 E. K. Woodman, J. G. K. Chaffey, P. A. Hopes, D. R. J. Hose and J. P. Gilday, Org. Process Res. Dev., 2009, 13, 106.

10 P. O'Connor, J. S. Wolinsky, C. Confavreux, G. Comi, L. Kappos, T. P. Olsson, H. Benzerdjeb, P. Truffinet, L. Wang, A. Miller and M. S. Freedman, N. Engl. J. Med., 2011, 365, 1293. 